\title{
Recombinant protein TRAIL-Mu3 enhances the antitumor effects in pancreatic cancer cells by strengthening the apoptotic signaling pathway
}

\author{
MIN HUANG ${ }^{1}$, CHENG YI $^{2}$, XIAN-ZHOU HUANG ${ }^{3}$, JUAN YAN $^{3}$, LI-JIA WEI ${ }^{3}$, \\ WEI-JU TANG ${ }^{4}$, SHOU-CHUN CHEN ${ }^{3}$ and YING HUANG ${ }^{5}$ \\ ${ }^{1}$ Department of Physiology, Chengdu Medical College, Chengdu, Sichuan 610000; \\ ${ }^{2}$ Department of Medical Oncology, West China Hospital, Sichuan University, Chengdu, Sichuan 610000; \\ ${ }^{3}$ Chengdu Huachuang Biotechnology Co., Ltd., Chengdu, Sichuan 610000; ${ }^{4}$ Department of Neurology, \\ The First People's Hospital of Longquanyi District, Chengdu, Sichuan 610000; ${ }^{5}$ Department of Pathophysiology, \\ West China School of Basic Medical Sciences and Forensic Medicine, \\ Sichuan University, Chengdu, Sichuan 610000, P.R. China
}

Received July 2, 2020; Accepted February 8, 2021

DOI: $10.3892 / 01.2021 .12699$

\begin{abstract}
Pancreatic cancer is a highly malignant type of cancer and its treatment remains a major challenge. The novel recombinant protein TNF-related apoptosis-inducing ligand (TRAIL)-Mu3 has been shown to exert stronger tumor inhibitory effects in colon cancer in vitro and in vivo compared with TRAIL. The present study investigated the antitumor effects of TRAIL-Mu3 on pancreatic cancer cells, and the possible mechanisms were further examined. Compared with TRAIL, TRAIL-Mu3 exhibited significantly higher cytotoxic effects on pancreatic cancer cell lines. The inhibitory effect of TRAIL-Mu3 on the viability of PANC-1 cells was shown to be a caspase-dependent process. The affinity of TRAIL-Mu3 to PANC-1 cell membranes was significantly enhanced compared with TRAIL. In addition, TRAIL-Mu3 upregulated death receptor (DR) expression in PANC-1 cells and promoted the redistribution of DR5 in lipid rafts. Western blotting results demonstrated that TRAIL-Mu3 activated the caspase cascade in a faster and more efficient manner compared with TRAIL in PANC-1 cells. Therefore, TRAIL-Mu3 enhanced the
\end{abstract}

Correspondence to: Dr Shou-Chun Chen, Chengdu Huachuang Biotechnology Co., Ltd., 88 Keyuan South Road, High-tech Zone, Chengdu, Sichuan 610000, P.R. China

E-mail: chen70257@126.com

Professor Ying Huang, Department of Pathophysiology, West China School of Basic Medical Sciences and Forensic Medicine, Sichuan University, Section 3, 17 Renmin South Road, Wuhou, Chengdu, Sichuan 610000, P.R. China

E-mail: huangying68@163.com

Key words: tumor necrosis factor-related apoptosis-inducing ligand (TRAIL), TRAIL-Mu3, death receptor, apoptosis, pancreatic cancer antitumor effects in pancreatic cancer cells by strengthening the apoptotic signaling pathway. The present study indicated the potential of TRAIL-Mu3 for the treatment of pancreatic cancer.

\section{Introduction}

Pancreatic cancer is a highly malignant type of tumor of the digestive system, with a 5-year survival rate of $3 \%$ (1). Most patients present with advanced stage disease at diagnosis, upon which surgery is no longer an option (2). Even after surgical resection, the estimated overall survival rate remains low $(20 \%)$ and most patients will develop metastatic disease within 5 years (3). The lethality of pancreatic cancer is attributed to several factors, including the lack of effective screening, delayed presentation and complex tumor biology and genetics (4). At present, there is no effective treatment for pancreatic cancer, especially in advanced stages, and there has been no successful breakthrough in the development of new targeted therapies (5). Therefore, there is an urgent need to identify effective therapeutics for patients with pancreatic cancer (6).

As a programmed death mechanism, apoptosis serves an important role in maintaining homeostasis (7). A number of oncogenic pathways inhibit apoptosis, and the imbalance of apoptosis has an important role in tumor occurrence and development (8). TNF-related apoptosis-inducing ligand (TRAIL) can induce apoptosis of various cancer cells while sparing most normal cells, and has been shown to be a relatively promising and effective anticancer agent $(9,10)$. TRAILinduced apoptosis is mediated by an extrinsic pathway via death receptor (DR)4 and/or DR5. The interaction between the DR Fas-associated protein with death domain (FADD) and pro-caspase- 8 promotes the formation of death-inducible signaling complex (DISC) (11). With the formation of DISC, pro-caspase- 8 is activated, which then activates caspase-3 (10). Caspase- 8 may also proteolytically process Bid to initialize the 
intrinsic pathway (12). However, a subsequent study found that a multitude of cancer cells avoid TRAIL-induced apoptosis in different ways, such as via loss of cell surface expression of TRAIL receptors and imbalance of stoichiometric ratios of pro- and anti-apoptotic proteins (12). Additionally, another study has revealed that the function of lipid rafts is associated with TRAIL resistance in NSCLC cells (13). Lipid rafts are membrane microdomains within the lipid bilayer structure containing special lipids and proteins, which provide a membrane aggregation platform for DRs and serve an important role in initiating death signaling transmission (14).

Most tumor cell membranes contain acid phospholipids (3-9\%), making the tumor cell surface negatively charged $(15,16)$. In a previous study $(17)$, the soluble TRAIL 114-121 amino acid coding sequence (VRERGPQR) was selected and constructed into the 'RRRRRRRR' sequence to obtain a novel TRAIL mutant, TRAIL-Mu3. The antitumor effects of TRAIL-Mu3 on colorectal cancer in vitro and in vivo were significantly improved (18). The present study investigated the antitumor effects of TRAIL-Mu3 on pancreatic cancer cells and its possible mechanism.

\section{Materials and methods}

Cell culture and treatment. MIAPaca-2 cells (Shanghai Institutes for Biological Sciences; Chinese Academy of Sciences) were maintained in RPMI-1640 medium (Thermo Fisher Scientific, Inc.) supplemented with $1 \mathrm{mM}$ sodium pyruvate and $10 \%$ fetal bovine serum (Thermo Fisher Scientific, Inc.). PANC-1 and PA-TU8988S cells (Shanghai Institutes for Biological Sciences; Chinese Academy of Sciences) were maintained in low-glucose DMEM (Thermo Fisher Scientific, Inc.) supplemented with $10 \%$ fetal bovine serum. All cells were incubated in $5 \% \mathrm{CO}_{2}$ at $37^{\circ} \mathrm{C}$. Cytotoxicity was evaluated using medium containing $10 \%$ Cell Counting Kit- 8 reagent (Dojindo Molecular Technologies, Inc.) for $1.5 \mathrm{~h}$ at $37^{\circ} \mathrm{C}$. Pancreatic cancer cells were treated with TRAIL-Mu3 (Initial concentration $0.1 / 1 / 100 \mu \mathrm{g} / \mathrm{ml}$ ) or TRAIL (Initial concentration 100/100/300 $\mu \mathrm{g} / \mathrm{ml}$ ) (Chengdu Huachuang Biotechnology Co., Ltd.) for $48 \mathrm{~h}$ at $37^{\circ} \mathrm{C}$. A microplate reader was used to measure the raw values at a wavelength of $490 \mathrm{~nm}$ (Infinite F50; Tecan Group, Ltd.). The criterium for sensitivity or resistance was the half maximal inhibitory concentration $\left(\mathrm{IC}_{50}<10 \mu \mathrm{g} / \mathrm{ml}\right.$, the cell was sensitive to the protein sample; $\mathrm{IC}_{50} \geq 10 \mu \mathrm{g} / \mathrm{ml}$, the cell was resistant to the protein sample). Cytotoxicity assays were performed in triplicate and repeated at least three times.

Assessment of apoptosis. PANC-1 cells $\left(2 \times 10^{6} / \mathrm{ml}\right)$ were seeded in 6-well plates and incubated with TRAIL-Mu3 or TRAIL $(0.0025 \mu \mathrm{g} / \mathrm{ml})$ for $24 \mathrm{~h}$ at $37^{\circ} \mathrm{C}$. Subsequently, the cells were collected and washed twice with cold phosphatebuffered saline (PBS). The cells were resuspended in $500 \mu \mathrm{l}$ $1 \mathrm{X}$ Annexin $\mathrm{V}$ binding buffer containing $5 \mu \mathrm{l}$ Annexin V-FITC and $5 \mu \mathrm{lPI}$ solution (Dojindo Molecular Technologies, Inc.). The percentage of early and late apoptotic cells was evaluated with a FACSCalibur instrument (Cytoflex; Beckman Coulter, Inc.) and analyzed using CytExpert 2.0 (Beckman Coulter, Inc.).

PANC-1 cells $\left(5 \times 10^{3} / \mathrm{ml}\right)$ were seeded in 96 -well plates, pretreated with or without the broad-spectrum caspase inhibitor Z-VAD-FMK (10 $\mu \mathrm{M}$; Selleck Chemicals) and incubated with TRAIL-Mu3 (initial concentration $0.1 \mu \mathrm{g} / \mathrm{ml}$ ) or TRAIL (initial concentration $0.1 \mu \mathrm{g} / \mathrm{ml}$ ) for $48 \mathrm{~h}$ at $37^{\circ} \mathrm{C}$. Cytotoxicity was evaluated using the Cell Counting Kit-8, as aforementioned.

Analysis of affinity by immunofluorescence. The Pierce FITC Antibody Labeling kit (Thermo Fisher Scientific, Inc.) was used to label TRAIL-Mu3 or TRAIL according to the manufacturer's instructions. PANC-1 cells $\left(5 \times 10^{4} / \mathrm{ml}\right)$ were seeded in 24-well plates that contained slides and then incubated with labeled TRAIL-Mu3 or TRAIL. After $1 \mathrm{~h}$ at $37^{\circ} \mathrm{C}$, cells were washed with PBS and fixed with $4 \%$ paraformaldehyde for $20 \mathrm{~min}$ at room temperature. Cells were then stained with DiI (Beyotime Institute of Biotechnology) for $10 \mathrm{~min}$ and Hoechst 33342 (Beyotime Institute of Biotechnology) for $5 \mathrm{~min}$ at room temperature. Antifade mounting medium (Beyotime Institute of Biotechnology) was used to mount the cells, and the samples were analyzed by fluorescence microscopy (magnification, x400; AX10 Imager A2; Carl Zeiss AG).

Analysis of the distribution of DRs in lipid rafts by immunofluorescence. PANC-1 cells $\left(5 \times 10^{4} / \mathrm{ml}\right)$ were seeded and incubated with TRAIL-Mu3 or TRAIL $(0.0025 \mu \mathrm{g} / \mathrm{ml})$ in 24-well plates with slides and fixed in $4 \%$ paraformaldehyde at $4^{\circ} \mathrm{C}$. After $20 \mathrm{~min}$, cells were blocked with $3 \%$ bovine serum albumin (BSA; Thermo Fisher Scientific, Inc.) for $30 \mathrm{~min}$ at room temperature. For double staining, anti-DR4 or anti-DR5 mouse monoclonal primary antibodies (1:100; cat. nos. sc-8411 and sc-166624, respectively; Santa Cruz Biotechnology, Inc.) were used to label the cells at $4^{\circ} \mathrm{C}$. After $1 \mathrm{~h}$, the cells were incubated with rhodamine-conjugated goat anti-mouse $\mathrm{IgG}$ secondary antibody (1:62.5; cat. no. sc-358922; Santa Cruz Biotechnology, Inc.) for $45 \mathrm{~min}$ at $4^{\circ} \mathrm{C}$. FITC-conjugated rabbit anti-choleratoxin B $(12.5 \mu \mathrm{g} / \mathrm{ml}$; cat. no. C1655; SigmaAldrich; Merck KGaA) was simultaneously added with the secondary antibody to stain the membrane rafts. Fluorescence microscopy (magnification, x400; AX10 Imager A2/AX10 Cam HRC; Carl Zeiss AG) was used to analyze the cells.

Western blot analysis. PANC-1 cells were seeded in a $60-\mathrm{mm}$ culture dish and incubated with TRAIL-Mu3 or TRAIL $(0.0025 \mu \mathrm{g} / \mathrm{ml})$ at $37^{\circ} \mathrm{C}$. After 2,4 and $6 \mathrm{~h}$, cells were collected and lysed at $4^{\circ} \mathrm{C}$ with $200 \mu \mathrm{l}$ buffer containing $1 \%$ Triton $\mathrm{X}-100$ and protease and phosphatase inhibitors. Protein concentration was determined using a bicinchoninic acid assay. Proteins (50 $\mu \mathrm{g} /$ lane) from lysed cells were separated via $15 \%$ SDS-PAGE and transferred to polyvinylidene difluoride membranes, which were blocked with TBS buffer containing 3\% BSA (Thermo Fisher Scientific, Inc.) for $2 \mathrm{~h}$ at room temperature and subsequently probed with primary antibodies overnight at $4^{\circ} \mathrm{C}$, followed by secondary antibodies for $2 \mathrm{~h}$ at $4^{\circ} \mathrm{C}$. Protein bands were visualized by electrochemiluminescence (Thermo Fisher Scientific, Inc.). Primary antibodies for caspase-3 (cat. no. 9665; 1:1,000), caspase-8 (cat. no. 9746; 1:1,000), $\beta$-actin (cat. no. 4970; 1:1,000) and poly (ADP-ribose) polymerase (PARP; cat. no. 9542; 1:1,000) were purchased from Cell Signaling Technology, Inc. HRP-conjugated anti-mouse IgG (cat. no. 7076; 1:1,000) and 

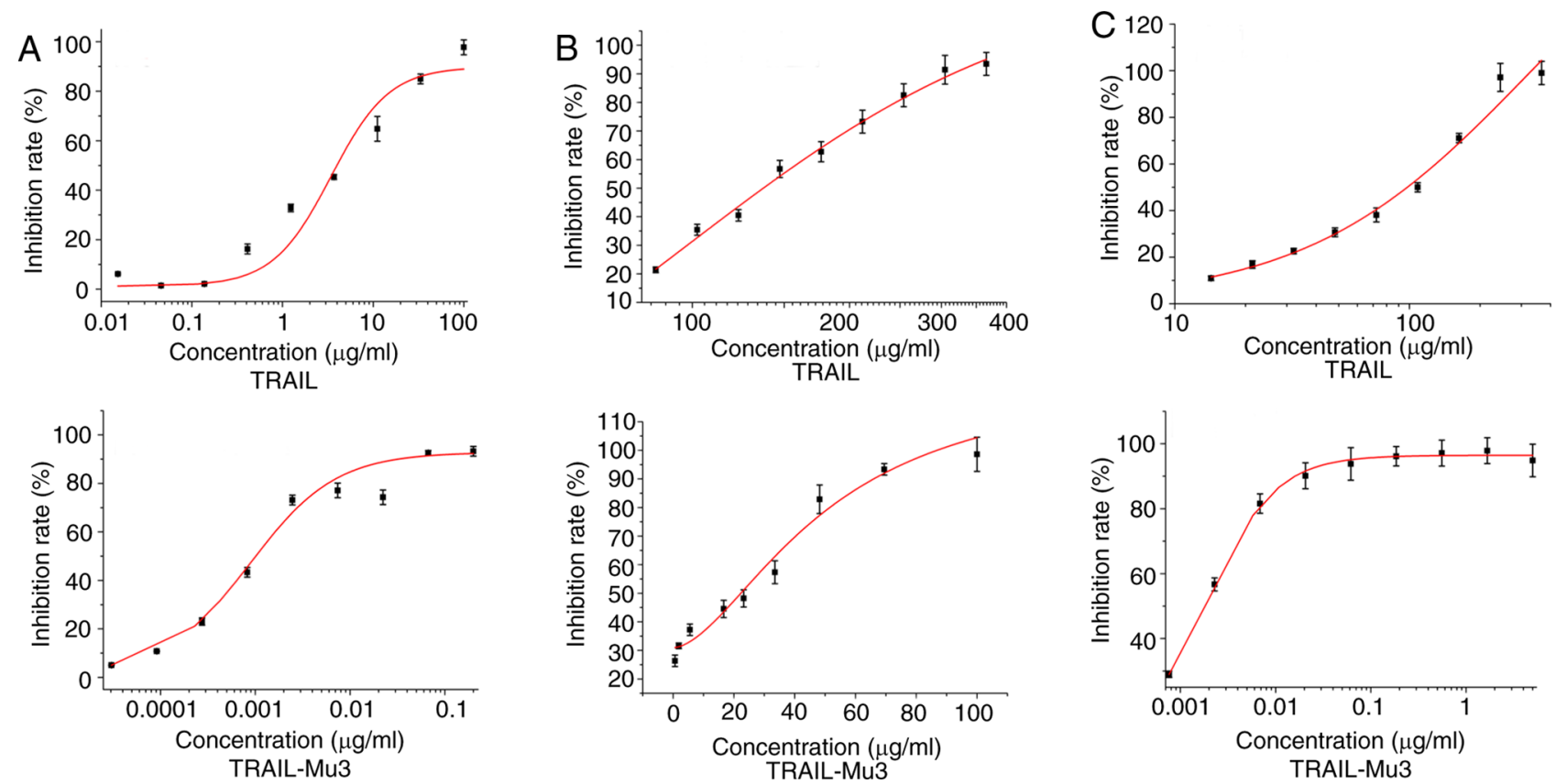

Figure 1. Antitumor activity of TRAIL-Mu3 in pancreatic cancer cell lines. (A) MIAPaca-2, (B) PA-TU8988S and (C) PANC-1 cells. TRAIL-Mu3, recombinant TNF-related apoptosis-inducing ligand.

Table I. Comparison of $\mathrm{IC}_{50}$ values between pancreatic cancer cell lines.

\begin{tabular}{lrr}
\hline \multirow{2}{*}{ Cell line } & \multicolumn{2}{c}{$\mathrm{IC}_{50}, \mu \mathrm{g} / \mathrm{ml}$} \\
\cline { 2 - 3 } & \multicolumn{1}{c}{ TRAIL } & \multicolumn{1}{c}{ TRAIL-Mu3 } \\
\hline MIAPaca-2 & $5.7252 \pm 0.9613$ & $0.0008 \pm 0.0002^{\mathrm{a}}$ \\
PA-TU8988S & $128.4667 \pm 2.2460$ & $30.4600 \pm 2.7700^{\mathrm{b}}$ \\
PANC-1 & $145.1920 \pm 5.5636$ & $0.0028 \pm 0.0017^{\mathrm{c}}$ \\
\hline
\end{tabular}

${ }^{\mathrm{a}} \mathrm{P}<0.001,{ }^{\mathrm{b}} \mathrm{P}<0.00001$ and ${ }^{\mathrm{c}} \mathrm{P}<0.000001$ vs. TRAIL. $\mathrm{IC}_{50}$, half maximal inhibitory concentration; TRAIL-Mu3, recombinant TNF-related apoptosis-inducing ligand.

anti-rabbit IgG (cat. no. 7074; 1:1,000) secondary antibodies were purchased from Cell Signaling Technology, Inc. ImageJ. JS (powered by ImJoy) was used for densitometry.

In parallel, PANC-1 cells $\left(5 \times 10^{3} / \mathrm{ml}\right)$ were seeded in 96-well plates, incubated with TRAIL-Mu3 or TRAIL $(0.0025 \mu \mathrm{g} / \mathrm{ml})$ for 2,4 and $6 \mathrm{~h}$ at $37^{\circ} \mathrm{C}$. Cytotoxicity was evaluated using the Cell Counting Kit-8, as aforementioned.

Flow cytometric analysis of DRs. PANC-1 cells $(2 \times 106 / \mathrm{ml})$ were seeded in 6-well plates and incubated with TRAIL-Mu3 or TRAIL $(0.0025 \mu \mathrm{g} / \mathrm{ml})$ for $24 \mathrm{~h}$ at $37^{\circ} \mathrm{C}$. Subsequently, cells were collected and resuspended in PBS containing $1 \%$ BSA. Next, FITC-labeled mouse anti-human DR4 (cat. no. A15746) or DR5 monoclonal antibodies (cat. no. A15750) (both 1:20; both from Thermo Fisher Scientific, Inc.) were added for $30 \mathrm{~min}$ at $4^{\circ} \mathrm{C}$. FITC-labeled control $\mathrm{IgG}$ isotypes (1:20; cat. no. MA5-18096; Thermo Fisher Scientific, Inc.) were used to assess non-specific staining at $4^{\circ} \mathrm{C}$. After $30 \mathrm{~min}$, a
FACSCalibur instrument (CytoFlex; Beckman Coulter, Inc.) and CytExpert 2.0 (Beckman Coulter, Inc.) were used to analyze the cells.

Statistical analysis. SPSS software (version 19.0; IBM Corp.) or OriginPro software (version 9.0; OriginLab) were used to perform computer-based statistical analysis. Results were presented as the mean $\pm \mathrm{SD}$ of at least three different experiments. Statistical significance was evaluated using unpaired Student's t-test for comparisons between 2 groups and one-way ANOVA followed by Tukey's post-hoc test for comparisons among $>2$ groups. $\mathrm{P}<0.05$ was considered to indicate a statistically significant difference.

\section{Results}

Cytotoxic ability of TRAIL-Mu3. The present study assessed the cytotoxic ability of TRAIL-Mu3 in MIAPaca-2, PA-TU8988S and PANC-1 cells. TRAIL-Mu3 exhibited markedly higher cytotoxicity on pancreatic cancer cell lines compared with TRAIL (Fig. 1A-C). A significant decrease in the $\mathrm{IC}_{50}$ of TRAIL-Mu3 was observed in the three cancer cell lines compared with TRAIL (Table I).

Pro-apoptotic effects of TRAIL-Mu3 are significantly improved and TRAIL-Mu3-induced PANC-1 cell apoptosis is dependent on the caspase cascade. The present study selected the PANC-1 cell line, which is TRAIL-resistant and TRAILMu3-sensitive, for subsequent experiments. The apoptosis rate was significantly higher in the TRAIL-Mu3 group compared with in the TRAIL group (Fig. 2A). TRAIL-Mu3 exhibited significantly higher antitumor activity compared with TRAIL at each tested dose (Fig. 2B). However, when PANC-1 cells were pretreated with the broad-spectrum caspase 

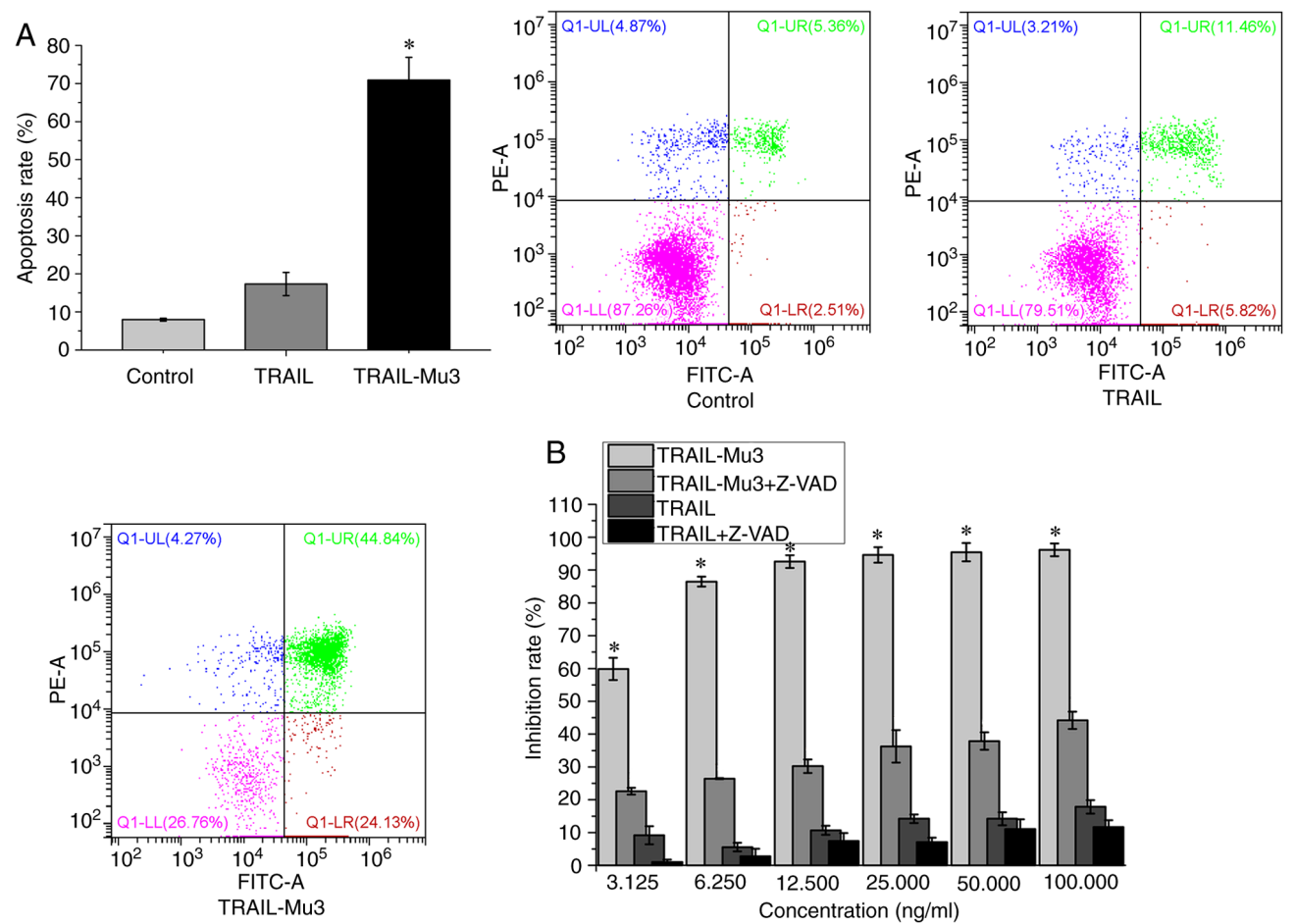

Figure 2. Apoptosis analysis in PANC-1 cells. (A) Pro-apoptotic abilities of TRAIL-Mu3 were significantly improved compared with TRAIL. "P<0.00001 vs. control and TRAIL. (B) Cell death induced by TRAIL-Mu3 in PANC-1 cells was suppressed by the broad-spectrum caspase inhibitor Z-VAD-FMK. ${ }^{*} \mathrm{P}<0.00001$ vs. TRAIL-Mu3+Z-VAD and TRAIL. TRAIL-Mu3, recombinant TNF-related apoptosis-inducing ligand.
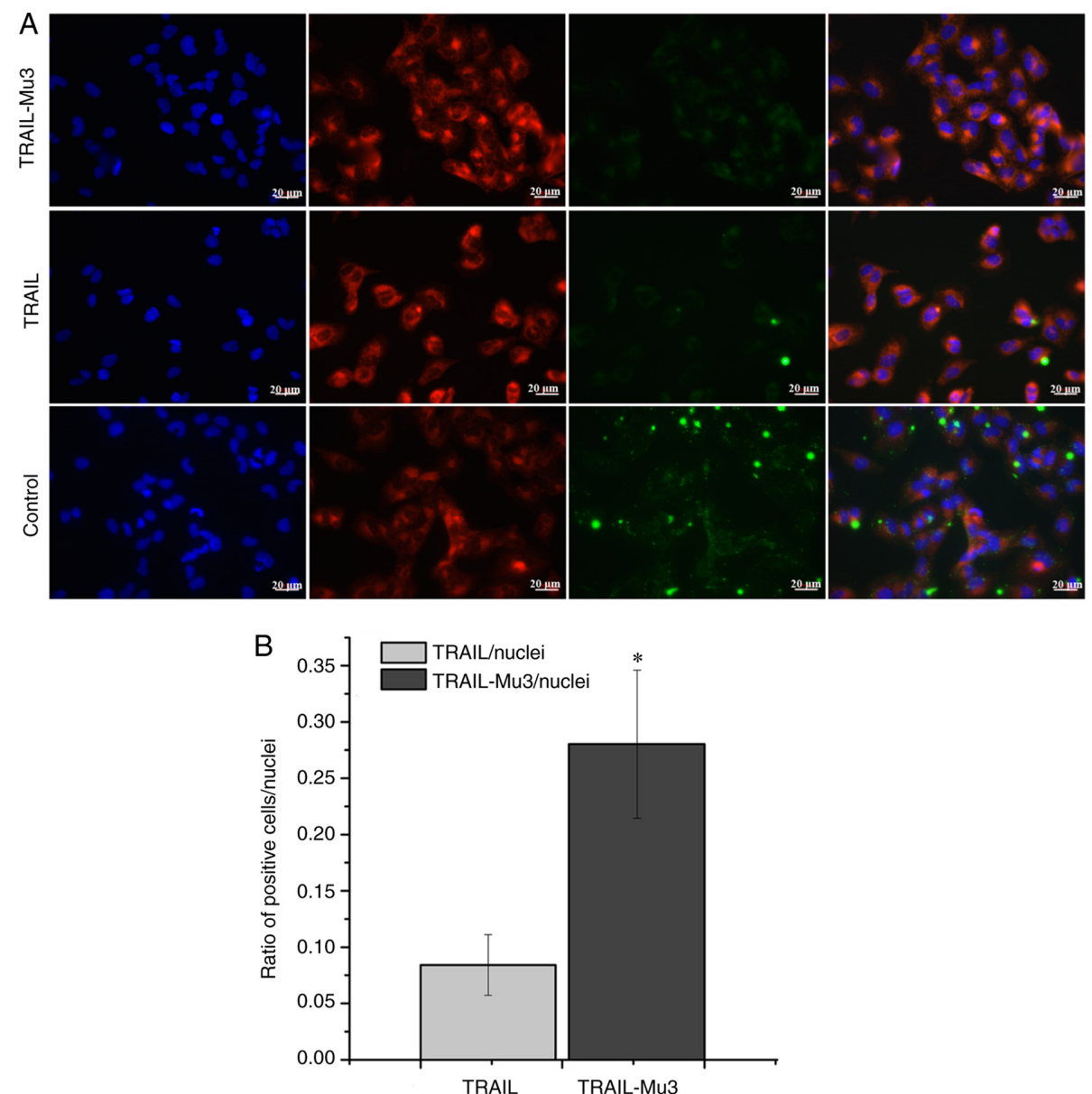

Figure 3. Affinity of TRAIL-Mu3 to PANC-1 cell membranes is significantly enhanced. (A) Cell nuclei were stained with Hoechst 33342 (blue) and cell membranes were stained with DiI (red). TRAIL-Mu3 or TRAIL were labeled with FITC (green). Scale bar, $20 \mu \mathrm{m}$. (B) Quantification of the signal expressed as a ratio of TRAIL- or TRAIL-Mu3-positive cells to nuclei number. "P<0.001 vs. TRAIL. TRAIL-Mu3, recombinant TNF-related apoptosis-inducing ligand. 

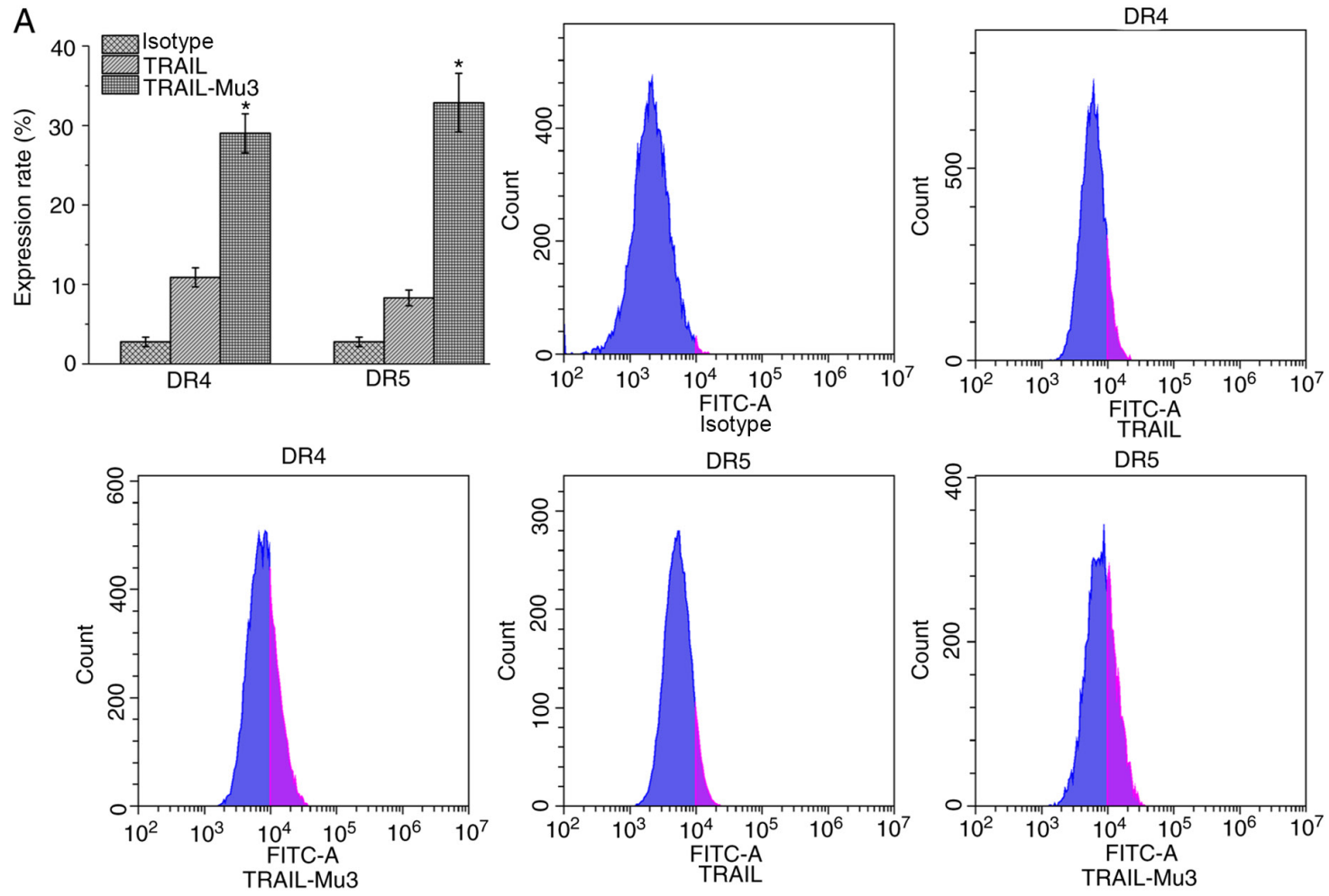

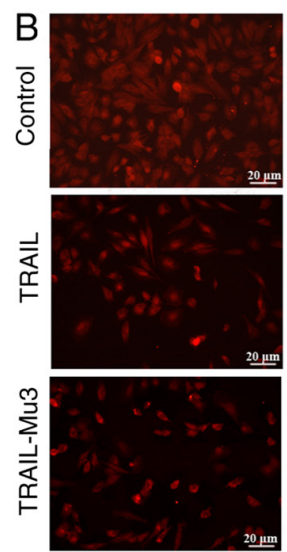

Rhodamine-DR4
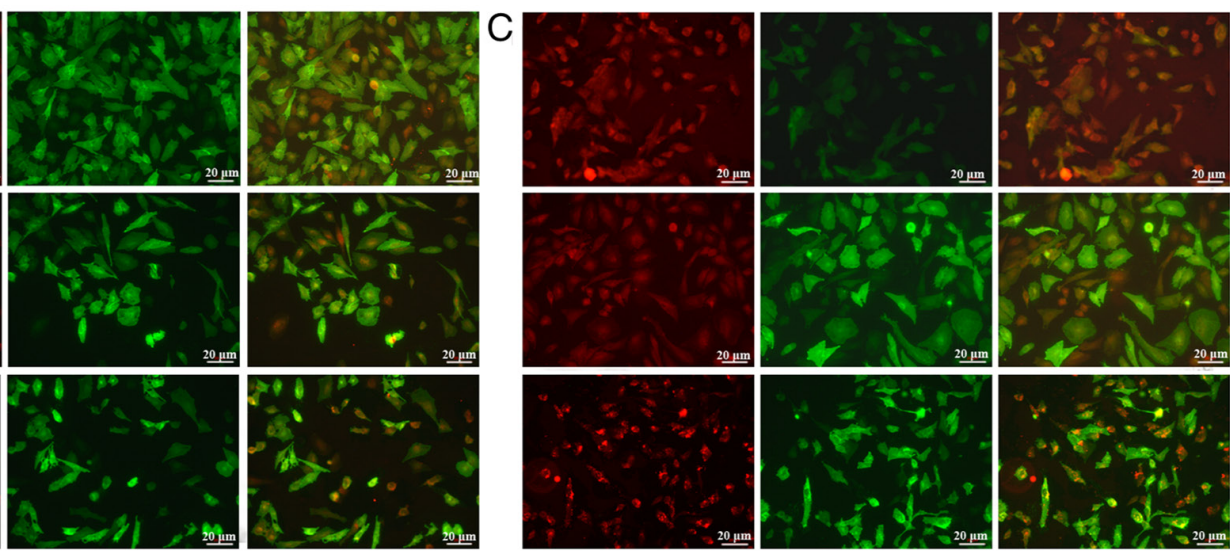

Merged

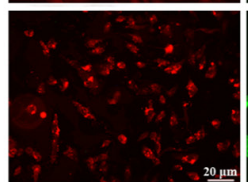

Rhodamine-DR5

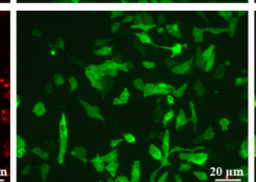

FITC-Ctx

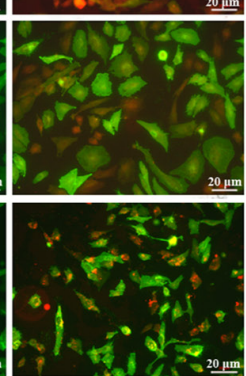

Merged

Figure 4. Effects of TRAIL-Mu3 on the expression levels and distribution of DRs. (A) TRAIL-Mu3 upregulated DR4 and DR5 expression in PANC-1 cells. ${ }^{*} \mathrm{P}<0.001$ vs. TRAIL. (B) TRAIL-Mu3 and TRAIL had no effect on the distribution of DR4 in lipid rafts, while (C) TRAIL-Mu3 promoted DR5 clustering into lipid rafts. Lipid rafts were stained with FITC-conjugated rabbit anti-Ctx (green) and DR4/DR5 was counterstained with rhodamine (red). Scale bar, $20 \mu \mathrm{m}$. TRAIL-Mu3, recombinant TNF-related apoptosis-inducing ligand; DR, death receptor; Ctx, choleratoxin B.

inhibitor Z-VAD-FMK, the antitumor activity of TRAIL and TRAIL-Mu3 was inhibited (Fig. 2B).

Affinity of TRAIL-Mu3 to PANC-1 cell membranes is significantly enhanced. Immunofluorescence assays were performed to assess the difference in affinity between TRAIL-Mu3 and TRAIL in PANC-1 cells. Following exposure to labeled TRAIL-Mu3 and TRAIL for $1 \mathrm{~h}$, PANC-1 cells were found to combine with a large amount of Green fluorescence in the TRAIL-Mu3 group, but this was not observed for the TRAIL group (Fig. 3A). The quantification of the signal expressed as a ratio of TRAIL or TRAIL-Mu3-positive cells to the number of nuclei is shown in Fig. 3B, indicating that the ratio of TRAIL-Mu3-positive cells/nuclei was significantly increased compared with the ratio of TRAIL-positive cells/nuclei.
TRAIL-Mu3 upregulates DR expression and promotes DR5 clustering into lipid rafts in PANC-1 cells. TRAIL-induced apoptosis is mediated by an extrinsic pathway via DR4 and DR5 (11). Therefore, the cell surface expression levels of DR4 and DR5 were evaluated by flow cytometry. Compared with the TRAIL group, DR4 and DR5 expression was increased in the TRAIL-Mu3 group (Fig. 4A). Cells treated with or without TRAIL or TRAIL-Mu3 for $24 \mathrm{~h}$ were assessed by immunofluorescence. The samples were stained using antibodies against DR4, DR5 and FITC-coupled choleratoxin B (FITC-Ctx), which forms a complex with the raft GM1-ganglioside component. In the TRAIL-Mu3 group, DR5 colocalized with FITC-Ctx, but this was not observed in the TRAIL group; no DR4 colocalization with FITC-Ctx was observed in both TRAIL and TRAIL-Mu3 groups (Fig. 4B and C). 

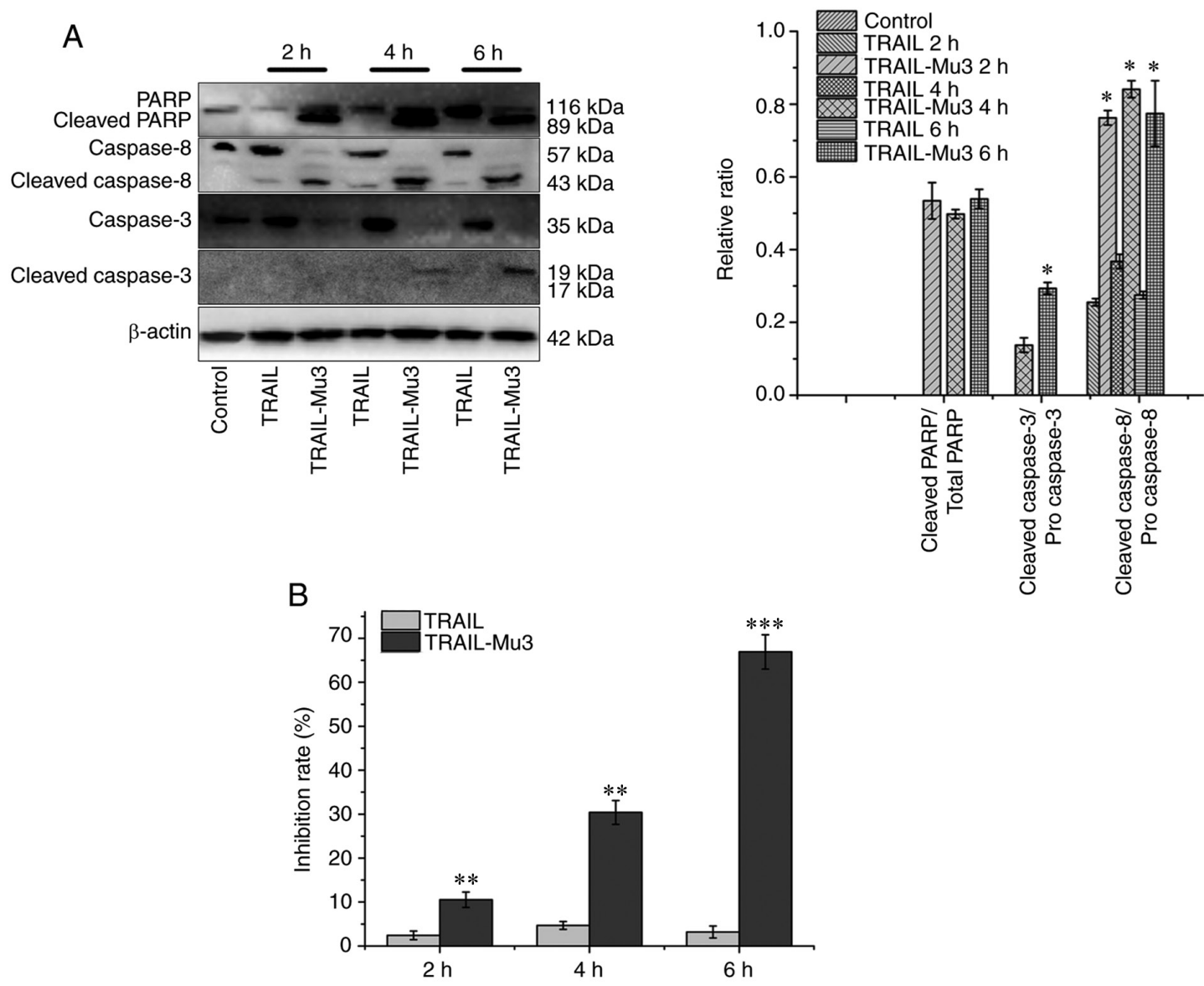

Figure 5. Expression levels of apoptosis-associated proteins. (A) Relative protein expression levels of cleaved caspase-3, cleaved caspase-8 and cleaved PARP. ${ }^{*} \mathrm{P}<0.05$ vs. TRAIL. Some bars are not shown since no cleaved protein was detected. (B) Antitumor activity of TRAIL-Mu3 and TRAIL at 2, 4 and $6 \mathrm{~h}$. ${ }^{* *} \mathrm{P}<0.001$ and ${ }^{* * *} \mathrm{P}<0.0001$ vs. TRAIL. TRAIL-Mu3, recombinant TNF-related apoptosis-inducing ligand; PARP, poly (ADP-ribose) polymerase.

TRAIL-Mu3 activates the caspase cascade in a faster and more efficient manner compared with TRAIL in PANC-1 cells. Based on the western blot analysis, treatment with TRAIL did not result in caspase cleavage (mainly of caspase-3), while TRAIL-Mu3 induced cleavage of both caspases- 8 and -3 as early as $2 \mathrm{~h}$ (Fig. 5A). In a parallel experiment, the inhibition rate increased gradually after 2, 4 and $6 \mathrm{~h}$ in the TRAIL-Mu3 group (Fig. 5B). Cleavage of caspase-3 in PANC-1 cells may be essential in the TRAIL-Mu3 group, since its substrate PARP was also cleaved in the TRAIL-Mu3 group and the inhibition rate increased (Fig. 5A and $\mathrm{B}$ ).

\section{Discussion}

Pancreatic cancer is one of the most lethal types of malignant tumor, with rising death rates (19). Due to late detection of pancreatic cancer in advanced stages, minimal efficacy of currently available therapies and its extremely aggressive nature, it remains a challenging problem in the clinical field (20). TRAIL can induce apoptosis of cancer cells without causing toxicity in mice, which has led to the in-depth study of pro-apoptotic TRAIL receptor (TRAIL-R) signaling (9). To date, numerous biotherapeutic drug candidates that activate TRAIL-Rs have been developed $(10,21)$. However, the results of clinical trials with TRAIL-R agonists have been disappointing, due to inadequate delivery methods, poor agonistic activity of these agents and TRAIL resistance $(22,23)$. To translate these promising agents into clinical application, studies have aimed to develop TRAIL derivatives with higher therapeutic effects $(24,25)$.

The novel recombinant protein TRAIL-Mu3 used in the present study exhibited significantly higher cytotoxicity compared with TRAIL. TRAIL-Mu3 considerably decreased the $\mathrm{IC}_{50}$ in all cell lines tested, and was able to overcome TRAIL resistance of several pancreatic cancer cell lines. In addition, experimental results revealed that TRAIL-Mu3induced apoptosis in PANC-1 cells was greater compared with that induced by TRAIL. Our previous study demonstrated that TRAIL-Mu3 repressed the growth of PANC-1 xenografts in nude mice and investigated the possible mechanism of this effect (17). The present study then assessed the underlying mechanism of action of TRAIL-Mu3 to further understand the improvement in the biological activity of TRAIL-Mu3.

Based on immunofluorescence results, it was revealed that the affinity of TRAIL-Mu3 to PANC-1 cell membranes was markedly enhanced compared with that of TRAIL. Aside from the N-terminal amino acid coding sequence, TRAIL-Mu3 has a similar structure to soluble TRAIL. The N-terminal of the TRAIL-Mu3 sequence (amino acids 114-121) was constructed into the 'RRRRRRRR' sequence, thereby increasing the positive charge of TRAIL-Mu3 (17). It has been found that most tumor cell membranes contain acid phos- 
pholipids (3-9\%), making the tumor cell surface negatively charged $(15,16)$. Electrostatic interactions may enhance the affinity of TRAIL-Mu3 to cell membranes. A previous study has confirmed that one class of cell-penetrating peptides, including Arg-rich peptides, may penetrate cells through electrostatic interactions and hydrogen bonding, and seem to be energy-independent (26). TRAIL-Mu3 is Arg-rich with an increased positive charge, which may contribute to the enhanced affinity of TRAIL-Mu3 to cell membranes. With the increased affinity, the chance of TRAIL-Mu3 binding to the receptor is also increased, which may activate the extrinsic pathway inducing tumor cell apoptosis (27).

TRAIL-induced apoptosis is mediated by an extrinsic pathway via DR4 and DR5 (22). The flow cytometry assay results revealed that treatment with TRAIL-Mu3 increased DR4 and DR5 cell surface expression. Previous studies revealed that TRAIL toxicity in tumors can be regulated by TRAIL-R expression. Hu et al (28) reported that chaetospirolactone reversed the apoptotic resistance towards TRAIL in pancreatic cancer by upregulating DR4 expression. In addition, Yang et al (29) found that high HOX transcript antisense RNA (HOTAIR) expression increased the resistance of pancreatic cancer cells to TRAIL-induced apoptosis, and short hairpin RNA-mediated HOTAIR-knockdown in TRAIL-resistant PANC-1 cells sensitized them to TRAILinduced apoptosis via upregulation of DR5 expression. Notably, in the present study, TRAIL-Mu3 promoted DR5 clustering into lipid rafts. A previous study has confirmed that various compounds that promote the clustering of DRs into lipid rafts can account for TRAIL sensitization (13). $\mathrm{Xu}$ et al (30) reported that $\beta$-elemene increased the sensitivity of gastric cancer cells to TRAIL by promoting DR5 clustering and translocation of caspase-8, DR5 and FADD into lipid rafts.

A time-course assay was performed in PANC-1 cells in the present study. Cells were incubated with TRAIL and TRAIL-Mu3, followed by western blot analysis of activated caspase-8, caspase-3 and the corresponding substrate PARP. Compared with TRAIL, TRAIL-Mu3 activated the caspase cascade in a faster and more efficient manner. Caspase- 8 activation following ligation of DR4/DR5 by TRAIL is the apical caspase in the extrinsic pathway; subsequently, caspase- 3 is cleaved by activated caspase- 8 , followed by the cleavage of death substrates and cell death (31). PARP inactivated by caspase cleavage serves an important role in DNA repair (32). PARP cleavage by caspase- 3 is an important signal of apoptosis (33). In the present study, TRAIL-Mu3 enhanced the cleavage of caspase- 3 and its substrate PARP. A previous study has suggested that combined use of PARP inhibitors may sensitize pancreatic cancer cells to TRAIL (34).

In conclusion, the TRAIL-Mu3-enhanced pro-apoptotic potential in pancreatic cancer cells may be associated with the strengthening of the apoptotic signaling pathway by increased affinity to the cell membrane, upregulation of DR4 and DR5 expression, clustering of DR5 in lipid rafts and efficient caspase activation. However, there were several limitations in the present study. The molecular mechanisms by which TRAIL-Mu3 induced the redistribution of DR5 in lipid rafts were not very clear. Mechanistic studies should be performed in the future. Overall, the present study provided insight into the clinical application of TRAIL-Mu3 in the treatment of pancreatic cancer.

\section{Acknowledgements}

Not applicable.

\section{Funding}

The present study was supported by grants from the National Natural Scientific Foundation of China (grant no. 81372444) and the Natural Science Foundation of Chengdu Medical College (grant no. CYZ18-15).

\section{Availability of data and materials}

The datasets used and/or analyzed during the current study are available from the corresponding author on reasonable request.

\section{Authors' contributions}

$\mathrm{MH}$ performed the experiments and drafted the manuscript. $\mathrm{MH}$ and $\mathrm{YH}$ were responsible for confirming the authenticity of the data. CY and WJT performed the apoptosis and affinity analyses. JY and XZH performed the cytotoxicity assays. MH and LJW performed the analysis of the distribution of DRs in lipid rafts, western blot analysis and flow cytometric analysis of DRs. SCC and YH conceived and designed the experiments. All authors read and approved the final manuscript.

\section{Ethics approval and consent to participate}

Not applicable.

\section{Patient consent for publication}

Not applicable.

\section{Competing interests}

The authors declare that they have no competing interests.

\section{References}

1. Bray F, Ferlay J, Soerjomataram I, Siegel RL, Torre LA and Jemal A: Global cancer statistics 2018: GLOBOCAN estimates of incidence and mortality worldwide for 36 cancers in 185 countries. CA Cancer J Clin 68: 394-424, 2018.

2. Vincent A, Herman J, Schulick R, Hruban RH and Goggins M: Pancreatic cancer. Lancet 378: 607-620, 2011.

3. Wolpin BM: Pancreatic cancer. Hematol Oncol Clin North Am 29: xiii-xiv, 2015.

4. Chu LC, Goggins MG and Fishman EK: Diagnosis and detection of pancreatic cancer. Cancer J 23: 333-342, 2017.

5. Chatzizacharias NA, Tsai S, Griffin M, Tolat P, Ritch P, George B, Barnes C, Aldakkak M, Khan AH, Hall W, et al: Locally advanced pancreas cancer: Staging and goals of therapy. Surgery 163: 1053-1062, 2018.

6. Draper A: Updates in pancreatic cancer: Modest gains and hopeful targets. J Oncol Pharm Pract 25: 101-109, 2019.

7. Sadeghi S, Davoodvandi A, Pourhanifeh MH, Sharifi N, ArefNezhad R, Sahebnasagh R, Moghadam SA, Sahebkar A and Mirzaei H: Anti-cancer effects of cinnamon: Insights into its apoptosis effects. Eur J Med Chem 178: 131-140, 2019. 
8. Pistritto G, Trisciuoglio D, Ceci C, Garufi A and D'Orazi G: Apoptosis as anticancer mechanism: Function and dysfunction of its modulators and targeted therapeutic strategies. Aging (Albany NY) 8: 603-619, 2016.

9. von Karstedt S, Montinaro A and Walczak H: Exploring the TRAILs less travelled: TRAIL in cancer biology and therapy. Nat Rev Cancer 17: 352-366, 2017.

10. Zhong HH, Wang HY, Li J and Huang YZ: TRAIL-based gene delivery and therapeutic strategies. Acta Pharmacol Sin 40 1373-1385, 2019.

11. Yuan X, Gajan A, Chu Q, Xiong H, Wu K and Wu GS: Developing TRAIL/TRAIL death receptor-based cancer therapies. Cancer Metastasis Rev 37: 733-748, 2018.

12. Shahwar D, Iqbal MJ, Nisa MU, Todorovska M, Attar R, Sabitaliyevich UY, Farooqi AA, Ahmad A and Xu B: Natural product mediated regulation of death receptors and intracellular machinery: Fresh from the pipeline about TRAIL-mediated signaling and natural TRAIL sensitizers. Int J Mol Sci 20: 20, 2019.

13. Ouyang W, Yang C, Liu Y, Xiong J, Zhang J, Zhong Y, Zhang G, Zhou F, Zhou Y and Xie C: Redistribution of DR4 and DR5 in lipid rafts accounts for the sensitivity to TRAIL in NSCLC cells. Int J Oncol 39: 1577-1586, 2011

14. Aroui S, Brahim S, Hamelin J, De Waard M, Breard J and Kenani A: Conjugation of doxorubicin to cell penetrating peptides sensitizes human breast MDA-MB 231 cancer cells to endogenous TRAIL-induced apoptosis. Apoptosis 14: 1352-1365, 2009.

15. Papo N, Seger D, Makovitzki A, Kalchenko V, Eshhar Z, Degani $\mathrm{H}$ and Shai Y: Inhibition of tumor growth and elimination of multiple metastases in human prostate and breast xenografts by systemic inoculation of a host defense-like lytic peptide. Cancer Res 66: 5371-5378, 2006.

16. Kirson ED, Dbalý V, Tovarys F, Vymazal J, Soustiel JF, Itzhaki A, Mordechovich D, Steinberg-Shapira S, Gurvich Z, Schneiderman R, et al: Alternating electric fields arrest cell proliferation in animal tumor models and human brain tumors. Proc Natl Acad Sci USA 104: 10152-10157, 2007.

17. Huang M, Zhu H, Yi C, Yan J, Wei L, Yang X, Chen S and Huang Y: A novel TRAIL mutant-TRAIL-Mu3 enhances the antitumor effects by the increased affinity and the up-expression of DR5 in pancreatic cancer. Cancer Chemother Pharmacol 82: 829-838, 2018.

18. Zhu H, Yan J, Xu Q, Wei L, Huang X, Chen S and Yi C: TRAIL mutant membrane penetrating peptide alike (TMPPA) TRAIL-Mu3 enhances the antitumor effects of TRAIL in vitro and in vivo. Mol Med Rep 16: 9607-9612, 2017.

19. Neoptolemos JP, Kleeff J, Michl P, Costello E, Greenhalf W and Palmer DH: Therapeutic developments in pancreatic cancer: Current and future perspectives. Nat Rev Gastroenterol Hepatol 15: 333-348, 2018.

20. Spano C, Grisendi G, Golinelli G, Rossignoli F, Prapa M, Bestagno M, Candini O, Petrachi T, Recchia A, Miselli F, et al: Soluble TRAIL armed human MSC as gene therapy for pancreatic cancer. Sci Rep 9: 1788, 2019. https://doi.org/10.1038/ s41598-018-37433-6.
21. de Miguel D, Lemke J, Anel A, Walczak H and MartinezLostao L: Onto better TRAILs for cancer treatment. Cell Death Differ 23: 733-747, 2016.

22. Bellail AC, Qi L, Mulligan P, Chhabra V and Hao C: TRAIL agonists on clinical trials for cancer therapy: The promises and the challenges. Rev Recent Clin Trials 4: 34-41, 2009.

23. Lemke J, von Karstedt S, Zinngrebe J and Walczak H: Getting TRAIL back on track for cancer therapy. Cell Death Differ 21: 1350-1364, 2014

24. Legler K, Hauser C, Egberts JH, Willms A, Heneweer C, Boretius S, Röcken C, Glüer CC, Becker T, Kluge M, et al: The novel TRAIL-receptor agonist APG350 exerts superior therapeutic activity in pancreatic cancer cells. Cell Death Dis 9: 445, 2018.

25. Gallego-Lleyda A, De Miguel D, Anel A and Martinez-Lostao L: lipid nanoparticles decorated with TNF-related aptosis-inducing ligand (TRAIL) are more cytotoxic than soluble recombinant TRAIL in sarcoma. Int J Mol Sci 19: 19, 2018.

26. Gupta B, Levchenko TS and Torchilin VP: Intracellular delivery of large molecules and small particles by cell-penetrating proteins and peptides. Adv Drug Deliv Rev 57: 637-651, 2005.

27. Li R, Yang H, Jia D, Nie Q, Cai H, Fan Q, Wan L, Li L and $\mathrm{Lu} \mathrm{X}$ : Fusion to an albumin-binding domain with a high affinity for albumin extends the circulatory half-life and enhances the in vivo antitumor effects of human TRAIL. J Control Release 228: 96-106, 2016.

28. Hu W, Jia X, Gao Y and Zhang Q: Chaetospirolactone reverses the apoptotic resistance towards TRAIL in pancreatic cancer. Biochem Biophys Res Commun 495: 621-628, 2018.

29. Yang SZ, Xu F, Zhou T, Zhao X, McDonald JM and Chen Y: The long non-coding RNA HOTAIR enhances pancreatic cancer resistance to TNF-related apoptosis-inducing ligand. J Biol Chem 292: 10390-10397, 2017.

30. Xu L, Guo T, Qu X, Hu X, Zhang Y, Che X, Song H, Gong J, Ma R, Li C, et al: $\beta$-elemene increases the sensitivity of gastric cancer cells to TRAIL by promoting the formation of DISC in lipid rafts. Cell Biol Int 42: 1377-1385, 2018.

31. Beyer K, Baukloh AK, Stoyanova A, Kamphues C, Sattler A and Kotsch K: Interactions of tumor necrosis factor-related apoptosisinducing ligand (TRAIL) with the immune system: Implications for inflammation and cancer. Cancers (Basel) 11: 11, 2019.

32. Pilié PG, Tang C, Mills GB and Yap TA: State-of-the-art strategies for targeting the DNA damage response in cancer. Nat Rev Clin Oncol 16: 81-104, 2019.

33. Hsu HY, Lin TY, Hu CH, Shu DTF and Lu MK: Fucoidan upregulates TLR4/CHOP-mediated caspase-3 and PARP activation to enhance cisplatin-induced cytotoxicity in human lung cancer cells. Cancer Lett 432: 112-120, 2018

34. Xu F, Sun Y, Yang SZ, Zhou T, Jhala N, McDonald J and Chen Y: Cytoplasmic PARP-1 promotes pancreatic cancer tumorigenesis and resistance. Int J Cancer 145: 474-483, 2019.

This work is licensed under a Creative Commons Attribution-NonCommercial-NoDerivatives 4.0 International (CC BY-NC-ND 4.0) License. 